Charge Exchange Reaction in Dopant-Assisted Atmospheric Pressure Chemical Ionization and Atmospheric Pressure Photoionization

\title{
Vaikkinen, Anu
}

2016-08

Vaikkinen , A , Kauppila , T J \& Kostiainen , R 2016 , ' Charge Exchange Reaction in Dopant-Assisted Atmospheric Pressure Chemical Ionization and Atmospheric Pressure Photoionization ' , Journal of the American Society for Mass Spectrometry , vol. 27 , no. 8 , pp. 1291-1300 . https://doi.org/10.1007/s13361-016-1399-8

http://hdl.handle.net/10138/174484

https://doi.org/10.1007/s13361-016-1399-8

submittedVersion

Downloaded from Helda, University of Helsinki institutional repository.

This is an electronic reprint of the original article.

This reprint may differ from the original in pagination and typographic detail.

Please cite the original version. 
Published in:

Journal of the American Society for Mass Spectrometry 2016, 8, 1291-1300.

\section{Charge exchange reaction in dopant-assisted atmospheric pressure chemical ionization and atmospheric pressure photoionization}

Anu Vaikkinen, Tiina J. Kauppila, and Risto Kostiainen

Running title: Charge exchange in DA-APCI and DA-APPI

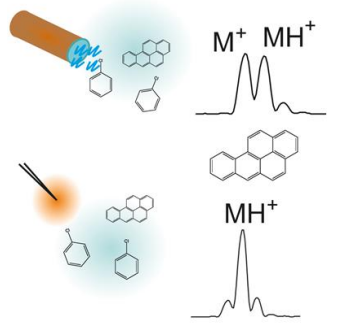

Add ress reprint requests to

Risto Kostiainen

Faculty of Pharmacy, University of Helsinki, P.O. Box 56 (Viikinkaari 5E), Fl-00014 University of Helsinki, Finland Tel: +358294159134

Fax: +358 294159556

E-mail: risto.kostiainen@helsinki.fi 


\begin{abstract}
The efficiencies of charge exchange reaction in dopant-assisted atmospheric pressure chemical ionization (DA$\mathrm{APCl}$ ) and dopant-assisted atmospheric pressure photoionization (DA-APPI) mass spectrometry (MS) were compared. Chlorobenzene was used as the dopant, and methanol/water (80/20) as the eluent. In both techniques, formation of radical cations of the analytes by charge exchange was observed, but in DA-APCl, the relative efficiency of charge exchange versus proton transfer was lower than in DA-APPI. This is suggested to be because in DA-APCl both dopant and solvent clusters can be ionized, and the formed reagent ions can react with the analytes via competing charge exchange and proton transfer reactions. In DA-APPI, on the other hand, the main reagents are dopant derived radical cations, which favors ionization of analytes via charge exchange. The efficiency of charge exchange in both DA-APPI and DA-APCI was shown to depend heavily on the eluent flow rate, with best efficiency seen at lowest flow rates studied $(0.05$ and $0.1 \mathrm{~mL} / \mathrm{min})$. Both DA-APCI and DA-APPI showed radical cation of chlorobenzene at $0.05-0.1 \mathrm{~mL} / \mathrm{min}$ flow rate, but at increasing flow rate, intensity of cholorobenzene $\mathrm{M}^{+}$. decreased and different reagent ion populations deriving from different gas-phase chemistry were recorded. The formation of these reagent ions explains the decreasing efficiency and the differences in charge exchange between the techniques.
\end{abstract}




\section{Introduction}

Atmospheric pressure chemical ionization (APCI) [1-3] is a widely used ion source for interfacing liquid chromatography (LC) with mass spectrometry (MS). APCl is typically used for small ( $<1000 \mathrm{u}$ ) molecules that are not sufficiently polar for efficient ionization by electrospray ionization (ESI). However, atmospheric pressure photoionization (APPI) [4] is generally perceived to be more efficient for low polarity compounds than APCl, as has been shown for polycyclic aromatic hydrocarbons (PAHs)[5], triterpenes [6], certain steroids [7], and pharmaceuticals [8].

In APCl, corona discharge in the $\mathrm{kV}$ range is used for primary ionization. This leads to rapid non-specific local ionization, and due to the large partial pressure of nitrogen from air, and nebulizer and counter gases in the source, the primary ionization produces mainly $\mathrm{N}_{2}{ }^{+}$ions (Reaction 1 , Table 1) [9]. Further gas-phase reactions tend to lead to formation of protonated solvent cluster ions in reversed phase (RP) LC-MS, where water and other protic solvents are present in the ion source (Reactions 2-5, Table 1) $[9,10]$. The protonated solvent (clusters) subsequently react with the analytes by proton transfer provided the proton affinity (PA) of the analyte is higher than that of the solvent (cluster) (Reaction 6, Table 1).

Commercially available APPI-M S ion sources are equipped with krypton discharge lamps that emit 10.0 and 10.6 eV photons, which can ionize any compounds with ionization energies (IE) below their energy. In dopant-assisted atmospheric pressure photoionization (DA-APPI), the primary ionization occurs by photoionization of a dopant (Reaction A, Table 1), an additional solvent that has IE below the energy of the photons, and which enhances the ionization efficiency of the analytes. Typically used DA-APPI dopants are e.g. toluene, anisole, chlorobenzene and acetone. Depending on the experimental conditions and the dopant, the formed dopant radical cation can selfprotonate (Reaction B, Table 1) or react with the eluent (Reaction C, Table 1). This is often followed by ionization of analyte by proton transfer (Reaction D, Table 1) similarly to APCI. The dopant radical cation can also react directly with the analytes through proton transfer or charge exchange (Reactions $E$, and $F$, respectively, Table 1). A lot of effort has been invested into tailoring the gas phase chemistry in APPI to favor charge exchange reaction in RPLC conditions [11, 12], because this reaction route makes possible the ionization of nonpolar compounds 
that are difficult to ionize by proton transfer reactions. One of the most successful charge exchange dopants has been chlorobenzene $[12,13]$, which has IE of $9.1 \mathrm{eV}[14]$. Importantly, the chlorobenzene radical cation does not go through proton transfer reaction with solvent clusters (Reaction C, Table 1) in RPLC-APPI-MS conditions [12]. In the case of APCl, a few literature reports exist, where dopants (i.e. benzene and chlorobenzene) that form stable radical cations have been used to enhance the ionization of analytes through charge exchange $[15,16]$, but DA-APCI has not been deeply explored.

Table 1. Comparison of ionization reactions in RPLC-APCI [9] and RPLC-DA-APPI [4]. $S=$ solvent, $D=$ dopant, $M=$ analyte, IE = ionization energy, $\mathrm{PA}=$ proton affinity, $\mathrm{RE}=$ recombination energy .

\begin{tabular}{|c|c|c|c|}
\hline \# & $\mathrm{APCl}$ & $\#$ & APPI \\
\hline 1 & $\begin{array}{l}\mathrm{N}_{2}+\mathrm{e}^{-} \rightarrow \mathrm{N}_{2}^{+}+2 \mathrm{e}^{-} \\
\mathrm{IE}\left(\mathrm{N}_{2}\right)=15.6 \mathrm{eV}[14]\end{array}$ & \multirow[t]{3}{*}{$\mathrm{A}$} & \multirow[t]{3}{*}{$\begin{array}{l}h v+D \rightarrow D^{+}+e^{-} \\
I E(D) \ll E(h v)=10.0 \text { and } 10.6 \mathrm{eV}\end{array}$} \\
\hline 2 & $\mathrm{~N}_{2}^{+}+2 \mathrm{~N}_{2} \rightarrow \mathrm{N}_{4}^{+}+\mathrm{N}_{2}$ & & \\
\hline 3 & $\begin{array}{l}\mathrm{N}_{4}^{++}+\mathrm{S} \rightarrow 2 \mathrm{~N}_{2}+\mathrm{S}^{+} \\
\mathrm{N}_{2}^{+}+\mathrm{S} \rightarrow \mathrm{N}_{2}+\mathrm{S}^{+} \\
\mathrm{IE}(\mathrm{S}) \& \mathrm{RE}\left(\mathrm{N}_{4}^{+} \cdot \mathrm{N}_{2}^{+{ }^{+}}\right)\end{array}$ & & \\
\hline 4 & $\mathrm{~S}^{+}+\mathrm{S} \rightarrow[\mathrm{S}+\mathrm{H}]^{+}+[\mathrm{S}-\mathrm{H}]$ & B & $\mathrm{D}^{+}+\mathrm{D} \rightarrow[\mathrm{D}+\mathrm{H}]^{+}+[\mathrm{D}-\mathrm{H}]^{\cdot}$ \\
\hline 5 & {$\left[S_{n-1}+H\right]^{+}+S+N_{2} \rightarrow\left[S_{n}+H\right]^{+}+N_{2}$} & $\mathrm{C}$ & $\begin{array}{l}D^{+}+S_{n} \rightarrow\left[S_{n}+H\right]^{+}+[D-H] \cdot \\
P A\left(S_{n}\right)>P A([D-H])\end{array}$ \\
\hline \multirow[t]{2}{*}{6} & \multirow[t]{2}{*}{$\begin{array}{l}{\left[S_{n}+H\right]^{+}+M \rightarrow[M+H]^{+}+S_{n}} \\
P A(M)>P A\left(S_{n}\right)\end{array}$} & $\mathrm{D}$ & $\begin{array}{l}{\left[S_{n}+H\right]^{+}+M \rightarrow[M+H]^{+}+S_{n}} \\
P A(M)>P A\left(S_{n}\right)\end{array}$ \\
\hline & & $\mathrm{E}$ & $\begin{array}{l}D^{+}+M \rightarrow[M+H]^{+}+[D-H] \\
P A(M)>P A([D-H])\end{array}$ \\
\hline 7 & $\begin{array}{l}\mathrm{S}^{+}+\mathrm{M} \rightarrow \mathrm{S}+\mathrm{M}^{+} \\
\mathrm{IE}(\mathrm{M}) \triangleleft \mathrm{E}(\mathrm{S})\end{array}$ & $\mathrm{F}$ & $\begin{array}{l}D^{+}+M \rightarrow D+M^{+} \\
I E(M) \triangleleft E(D)\end{array}$ \\
\hline
\end{tabular}

In this contribution, we study the efficiency of charge exchange reaction in DA-APPI and DA-APCI in RPLC-MS conditions with chlorobenzene as the dopant. Despite the frequent use of charge exchange reaction in DA-APPI and the similarity of the ionization mechanisms of APCI and APPI, to our best knowledge, such comparison has not been previously made. A representative set of 14 compounds with different polarities, sizes, and functional groups resulting in different gas-phase IEs and PAs, and a commercial mixture of polyaromatic hydrocarbons 
were chosen as model analytes. Structures of the compounds can be found in Figure S1 in Supplementary Material. Methanol/water (80:20) was used as the eluent, because methanol has lower PA compared to acetonitrile, and therefore shows better ionization efficiency for low PA compounds [17]. First of all, the feasibility of charge exchange reaction for the ionization of the model compounds by APCI, DA-APCI and DA-APPI was determined. Next, comparisons between DA-APCI and DA-APPI were made in eluent flow rate range 0.05 $0.8 \mathrm{ml} / \mathrm{min}$ in more detail. Solvent reagent ions formed in DA-APCI and DA-APPI were compared in order to explain the differences of the two techniques. Finally, the mechanism behind the observed differences in charge exchange efficiency between DA-APCI and DA-APPI are discussed.

\section{Experimental}

\section{Chemicals}

Apomorphine hydrochloride hemihydrate (98\%), benzo[a]pyrene (B[a]P, $\geq 97 \%)$, bisphenol $A(B P A, \geq 99 \%)$, cholesterol ( $\geq 99 \%)$, dihydrotestosterone (DT, $5 \alpha$-Androstan-17ß-ol-3-one, $\geq 97.5 \%)$, $\beta$-estradiol (E2, $\geq 98 \%)$, 4 nonylphenol $(99.8 \%)$, squalene $(\geq 98 \%)$, sulindac sulfide $(\geq 98 \%)$, testosterone $(\geq 98 \%)$, tonalide (6-acetyl1,1,2,4,4,7-hexanemethyltetralin, $\geq 98 \%)$, verapamil hydrochloride $(98 \%)$, anisole $(99.7 \%)$, chlorobenzene $(99.9$ $\%)$, toluene $(\geq 99.9 \%)$, dichloromethane $(\geq 99.8 \%)$, and methanol $(\geq 99.9 \%)$ were from Sigma-Aldrich Chemie GmbH (Steinheim, Germany). Luteolin was from Extrasynthese ( $\geq 99 \%$, Genay, France), ceramide C12 (ceramide C12:ON-lauroyl-D-erythro-sphingosine) was from Genzyme Pharmaceuticals (Liestal, Switzerland). TCL PAH mix (certified reference material 48905) was from Supelco (Bellefonte, PA, USA) and it contained $2000 \mu \mathrm{g} / \mathrm{mL}$ of acenaphthene, acenaphthylene, anthracene, benz[a]anthracene, benzo[a]pyrene, benzo[b]fluoranthene benzo[g,h,i]perylene, benzo[k]fluoranthene, chrysene, dibenz[a,h]anthracene, fluoranthene, fluorene, indeno[1,2,3-cd]pyrene, naphthalene, phenanthrene, and pyrene in benzene/dichloromethane. Water was purified by MilliQ water purifying system (M illipore, M olsheim, France).

Stock solutions of the standards were prepared in toluene (B[a]P, squalene), dichloromethane (ceramide $\mathrm{C} 12$ ), or methanol (rest of the analytes). Concentration of each stock solution was $10 \mathrm{mM}$ except for luteolin which 
was prepared at $1 \mathrm{mM}$, and BPA, which was prepared at $20 \mathrm{mM}$. All working solutions were prepared in methanol/water $(80 / 20 \mathrm{v} / \mathrm{v})$. The composition of the in-house prepared mixtures and gas-phase properties of the compounds can be found in Table 2. The PAH mix working solution had a concentration of $1 \mu \mathrm{g} / \mathrm{mL}$ for each analyte and the gas-phase properties of the compounds can be found in Table 3.

Table 2. Analyzed mixtures, and the gas-phase properties of the compounds based on literature reports and estimations deriving from structural homologies. IE =ionization energy, $\mathrm{PA}=$ proton affinity.

\begin{tabular}{|c|c|c|c|c|c|}
\hline \multirow[t]{2}{*}{ Compound } & \multirow[t]{2}{*}{$c(\mu \mathrm{M})$} & \multicolumn{4}{|c|}{ Estimated and previously reported gas-phase properties } \\
\hline & & $\mathrm{IE}(\mathrm{eV})$ & Reference for IE and notes & $\begin{array}{l}\text { PA } \\
(\mathrm{kJ} / \mathrm{mol})\end{array}$ & Reference for PA and notes \\
\hline \multicolumn{6}{|l|}{ Mixture 1} \\
\hline sulindac sulfide & 10 & 7.9 & $\begin{array}{l}\text { Estimated to be equal to IE of } \\
\text { methylphenylsulfide [14] }\end{array}$ & 873 & $\begin{array}{l}\text { Estimated to be equal to PA of } \\
\text { methylphenylsulfide[14] }\end{array}$ \\
\hline tonalide & 5 & 9.3 & $\begin{array}{l}\text { Estimated to be equal to IE of } \\
\text { acetophenone [14] }\end{array}$ & 917 & Calculated in [18] \\
\hline nonylphenol & 20 & 8.3 & $\begin{array}{l}\text { Estimated to be equal to IE of } \\
\text { cresol [14] }\end{array}$ & 814 & $\begin{array}{l}\text { Estimated to be equal to PA of } \\
\text { cresol [14] }\end{array}$ \\
\hline \multicolumn{6}{|l|}{ Mixture 2} \\
\hline $\begin{array}{l}\text { dihydrotestosterone } \\
\text { (DT) }\end{array}$ & 20 & 10.2 & Calculated in [19] & 841 & $\begin{array}{l}\text { Estimated to be equal to PA of } \\
\text { cyclohexanone [14] }\end{array}$ \\
\hline cholesterol & 1 & 8.5 & Measured in [20] & & \\
\hline bisphenol A (BPA) & 20 & 9.0 & Calculated in [21] & 817 & $\begin{array}{l}\text { Estimated to be equal to PA of } \\
\text { phenol [14] }\end{array}$ \\
\hline ceramide C12 & 1 & 9.8 & $\begin{array}{l}\text { Estimated to be equal to IE of } \\
\mathrm{N} \text {-methyl-formamide [14] }\end{array}$ & 851 & $\begin{array}{l}\text { Estimated to be equal to PA of N- } \\
\text { methyl-formamide [14] }\end{array}$ \\
\hline \multicolumn{6}{|l|}{ Mixture 3} \\
\hline apomorphine & 10 & 8.2 & $\begin{array}{l}\text { Estimated to be equal to IE of } \\
\text { biphenyl [14] }\end{array}$ & 971 & $\begin{array}{l}\text { Estimated to be equal to PA of 1- } \\
\text { methylpiperidine [14] }\end{array}$ \\
\hline $\begin{array}{l}\text { benzo[a]pyrene } \\
\text { (B[a]P) }\end{array}$ & 5 & 7.1 & [14] & 890 & [22] \\
\hline testosterone (T) & 5 & 10.2 & Calculated in [21] & 925 & Calculated in [23] \\
\hline verapamil & 1 & & & 980 & Calculated in [23] \\
\hline \multicolumn{6}{|l|}{ Mixture 4} \\
\hline estradiol (E2) & 10 & $\begin{array}{l}8.5 ; \\
9.0\end{array}$ & Calculated in [24]; [21] & 814 & $\begin{array}{l}\text { Estimated to be equal to PA of } \\
\text { cresol [14] }\end{array}$ \\
\hline luteolin & 10 & $\begin{array}{l}7.6 ; \\
6.1\end{array}$ & Calculated in [25]; [26] & & \\
\hline squalene & 10 & 8.6 & $\begin{array}{l}\text { Estimated to be equal to IE of } \\
\text { 2-methylpent-2-ene [14] }\end{array}$ & 812 & $\begin{array}{l}\text { Estimated to be equal to PA of 2- } \\
\text { methylpent-2-ene [14] }\end{array}$ \\
\hline
\end{tabular}


Table 3. Previously reported gas-phase properties of the PAHs in the commercial PAH mix.

\begin{tabular}{|l|l|l|l|l|l|l|}
\hline compound & formula & $\mathrm{M} r$ & $\mathrm{IE}(\mathrm{eV})$ & Ref for IE & $\begin{array}{l}\mathrm{PA} \\
(\mathrm{k} / \mathrm{mol})\end{array}$ & Ref for PA \\
\hline Naphthalene & $\mathrm{C}_{10} \mathrm{H}_{8}$ & 128 & 8.1 & {$[14]$} & 803 & {$[14]$} \\
\hline Acenaphthylene & $\mathrm{C}_{12} \mathrm{H}_{8}$ & 152 & 8.1 & {$[14]$} & 861 & {$[22]$} \\
\hline Acenaphthene & $\mathrm{C}_{12} \mathrm{H}_{10}$ & 154 & 7.8 & {$[14]$} & 852 & {$[14]$} \\
\hline Fluorene & $\mathrm{C}_{13} \mathrm{H}_{10}$ & 166 & 7.9 & {$[14]$} & 832 & {$[14]$} \\
\hline Anthracene & $\mathrm{C}_{14} \mathrm{H}_{10}$ & 178 & 7.5 & {$[14]$} & 877 & {$[14]$} \\
\hline Phenanthrene & $\mathrm{C}_{14} \mathrm{H}_{10}$ & 178 & 7.9 & {$[14]$} & 826 & {$[14]$} \\
\hline Pyrene & $\mathrm{C}_{16} \mathrm{H}_{10}$ & 202 & 7.4 & {$[14]$} & 869 & {$[14]$} \\
\hline Fluoranthene & $\mathrm{C}_{16} \mathrm{H}_{10}$ & 202 & 7.9 & {$[14]$} & 829 & {$[14]$} \\
\hline Chrysene & $\mathrm{C}_{18} \mathrm{H}_{12}$ & 228 & 7.6 & {$[14]$} & 841 & {$[14]$} \\
\hline Benz[a]anthracene & $\mathrm{C}_{18} \mathrm{H}_{12}$ & 228 & 7.5 & {$[14]$} & 869 & {$[22]$} \\
\hline Benzo[a]pyrene & $\mathrm{C}_{20} \mathrm{H}_{12}$ & 252 & 7.1 & {$[14]$} & 890 & {$[22]$} \\
\hline Benzo[b]fluoranthene & $\mathrm{C}_{20} \mathrm{H}_{12}$ & 252 & 8.4 & Calculated in [27] & & \\
\hline Benzo[k]fluoranthene & $\mathrm{C}_{20} \mathrm{H}_{12}$ & 252 & 8.2 & Calculated in [27] & 856 & {$[22]$} \\
\hline $\begin{array}{l}\text { Indeno[1,2,3- } \\
\text { cd]pyrene }\end{array}$ & $\mathrm{C}_{22} \mathrm{H}_{12}$ & 276 & 8.0 & Calculated in [27] & & \\
\hline Benzo[g,h,i]perylene & $\mathrm{C}_{22} \mathrm{H}_{12}$ & 276 & 7.2 & {$[14]$} & 876 & {$[14]$} \\
\hline Dibenz[a,h]anthracene & $\mathrm{C}_{22} \mathrm{H}_{14}$ & 278 & 7.4 & {$[14]$} & & \\
\hline
\end{tabular}

\section{Flow injection mass spectrometry}

Flow injection was performed using an Acquity UPLC (Waters, Milford, M A, USA) with methanol/water (80/20) as the eluent. The injection volume was $10 \mu \mathrm{L}$. Dopant (chlorobenzene at $10 \%$ of eluent flow rate) was mixed with the eluent flow via a PEEK t-piece prior to ion source. Agilent 1100 series capillary LC (Agilent Technologies Inc., Santa Clara, CA, USA) was used to degas and pump the dopant at flow rates $\leq 20 \mu \mathrm{L} / \mathrm{min}$ and an Agilent 1100 series HPLC degasser and pump at flow rates greater than $20 \mu \mathrm{L} / \mathrm{min}$. The analytes were ionized in an orthogonal commercial APCI source (Agilent), and the ions were detected by Agilent $6410 \mathrm{QQQ}$. For APPI, the APCI needle was removed and replaced by a krypton discharge vacuum UV lamp and a lamp power source from a commercial APPI ion source (Agilent). All experiments were conducted in positive ion mode. The ion source heater temperature was set at $450{ }^{\circ} \mathrm{C}$ and the nebulizer gas at $20 \mathrm{psi}$. Flow rate and temperature of the counter gas were $5 \mathrm{~L} / \mathrm{min}$ and $350^{\circ} \mathrm{C}$, respectively. Capillary voltage was $3500 \mathrm{~V}$ and corona current was $4 \mu \mathrm{A}$ in $\mathrm{APCl}$ and 0 $\mu \mathrm{A}$ in APPI. Fragmentor voltage was set to 113 and $30 \mathrm{~V}$ for studying the analyte and solvent ions, respectively. 
Scanned m/z range was 120-600 for analyte ions and 10-200 for solvent ions. Each analyte mixture was injected four times at all studied experimental conditions, while the solvent ion spectrum was recorded for 1 min.

\section{Results}

Observed ions

First, $\mathrm{APCl}, \mathrm{DA}-\mathrm{APCl}$ and DA-APPI were compared in typical $\mathrm{APCl}$ conditions at $0.8 \mathrm{~mL} / \mathrm{min}$ eluent flow rate. A great difference between the techniques was observed in background ion signals, as an order of magnitude lower total ion count was achieved in APCl compared to the dopant-assisted techniques at $\mathrm{m} / \mathrm{z}$ range $120-600$. This was partly due to a few abundant ions possibly deriving from the dopant e.g. at $\mathrm{m} / \mathrm{z} 128$ in DA-APCl and at $\mathrm{m} / \mathrm{z}$ 124 in DA-APPI, but also due to increased chemical noise that was especially high below $\mathrm{m} / \mathrm{z} 300$. After determining the background signal, the ionization of the model analytes was studied by APCl, DA-APCl, and DAAPPI. The results are given in Table 4.

In $\mathrm{APCl}$ without a dopant, the main species for most analytes were $[\mathrm{M}+\mathrm{H}]^{+}$and $\left[\mathrm{MH}-\mathrm{H}_{2} \mathrm{O}\right]^{+}$ions. In addition, other minor fragment ions were observed. Nonylphenol and PAHs with less than 14 carbons were not detected, and BPA showed a fragment at $\mathrm{m} / \mathrm{z} 135\left(\left[\mathrm{MH}-\mathrm{C}_{6} \mathrm{H}_{5} \mathrm{OH}\right]^{+}\right)$. Radical cations of the analytes were not observed. In DAAPCI $[\mathrm{M} \mathrm{HH}]^{+}, \mathrm{M}^{+}$, and fragment ions were detected depending on the analyte. Ceramide C12, cholesterol, DT, and testosterone showed signals only for the protonated species with or without water or hydrogen loss. For apomorphine, $\mathrm{B}[\mathrm{a}] \mathrm{P}, \mathrm{BPA}, \mathrm{E} 2$, sulindac sulfide, squalene and the $\mathrm{C}_{20} \mathrm{H}_{12}$ and $\mathrm{C}_{22} \mathrm{H}_{12}$ signals of the PAH mixture, $[\mathrm{M}+\mathrm{H}]^{+}$was the main species, but it was accompanied by a small amount of radical cations. Nonylphenol, fluorene (PAH mix), the $\mathrm{C} 14-\mathrm{C} 18$ PAHs and dibenz[a, $h$ ]anthracene $\left(\mathrm{C}_{22} \mathrm{H}_{14}\right)$ in the PAH mix showed mainly radical cations in DA-APCl. For BPA, the radical cation was observed, but the main ion was a fragment at $\mathrm{m} / \mathrm{z} 213$. Deducing from the structure of BPA, the fragment is most likely a resonance stabilized carbocation, which is formed by the loss of a methyl group from the radical cation. Tonalide showed the $[M+H]^{+}$ion and a fragment at $\mathrm{m} / \mathrm{z} 243$. The detection of naphthalene was hindered by an abundant background ion at the same mass with the analyte $\mathrm{M}^{+}$. 
at $\mathrm{m} / \mathrm{z}$ 128. DA-APPI showed mainly the same $[\mathrm{M}+\mathrm{H}]^{+}, \mathrm{M}^{+}$, and fragment ions as DA-APCl. In DA-APPI, a background ion at $\mathrm{m} / \mathrm{z} 154$ disturbed the detection of acenaphthene.

\section{Effect of flow rate}

Since DA-APPI has been reported to give the best performance at lower eluent flow rates [8, 28-30] than typically used in $\mathrm{APCl}$, we tested if this is the case also in DA-APCl. The flow rate of the dopant was kept at $10 \%$ of the eluent flow rate. Flow rate dependence of $A P C I$ and DA-APPI was measured as a reference. Examples of the results can be found in Figure 1, and data for all other studied analytes is given in Figure S2 of Supplementary M aterial. In DA-APCl, the trend for peak areas of analyte radical cations (e.g. B[a]P, nonylphenol and PAH-mix $\mathrm{C}_{16} \mathrm{H}_{10}$ in Figure 1) was clear: $0.1 \mathrm{~mL} / \mathrm{min}$ flow rate gave the largest peak areas, and decreasing or increasing the flow rate resulted in decreasing peak areas. Also in DA-APPI, the largest peak areas were obtained at lowest flow rates studied $(0.05-0.1 \mathrm{~mL} / \mathrm{min})$, but the peak areas decreased less steeply than in DA-APCI when the flow rate of the eluent was increased. In cases of $[\mathrm{M}+\mathrm{H}]^{+}$and $\left[\mathrm{MH}-\mathrm{H}_{2} \mathrm{O}\right]^{+}$ions, there were no uniform trends, but the flow rate dependence of the peak area varied from analyte to analyte and between the three techniques. APCI without a dopant gave an unstable signal at $0.2 \mathrm{~mL} / \mathrm{min}$ flow rate resulting in low peak areas for the analytes. At other flow rates studied, the signals were stable and the peak areas for PAHs, BPA, luteolin, squalene, sulindac sulfide, tonalide, and DT were largest at 0.05 and $0.1 \mathrm{~mL} / \mathrm{min}$, and the rest of the studied analytes gave somewhat similar peak areas at low $(0.05$ and $0.1 \mathrm{~mL} / \mathrm{min})$ and high $(0.4-0.8 \mathrm{~mL} / \mathrm{min})$ flow rates.

Secondly, the effect of the flow rate of the dopant was measured in DA-APCI. The flow rate of the eluent was kept constant at $0.8 \mathrm{~mL} / \mathrm{min}$, and the flow rate of the dopant was varied between $0-20 \%$ of the eluent flow rate. Representative examples of the results are given in Figure S3 of Supplementary Material: the peak areas of analyte radical cations increased somewhat linearly as the flow rate of the dopant increased, while the peak areas for $[\mathrm{M}+\mathrm{H}]^{+}$ions were somewhat constant or decreased mildly as the flow rate was increased. 
Table 4. Ions observed by APCI, DA-APCl and DA-APPI. The flow rate of the eluent was $0.8 \mathrm{~mL} / \mathrm{min}$. Ions with relative abundance greater than 10 $\%$ are reported and average relative abundance and tentative identification are shown in parenthesis. $*$ corrected for natural ${ }^{13} \mathrm{C}$ isotope of $\mathrm{M}{ }^{+}$ or $[\mathrm{M}-\mathrm{H}]^{+}$ion.

\begin{tabular}{|c|c|c|c|c|c|c|c|c|c|c|}
\hline \multirow[t]{3}{*}{ Compound } & \multirow{3}{*}{$\begin{array}{c}\mathrm{M}_{\text {mon }} \\
\text { oisotopi } \\
\mathrm{c}\end{array}$} & \multicolumn{9}{|c|}{ Observed ions } \\
\hline & & \multicolumn{3}{|c|}{$\mathrm{APCl}$ (without dopant) } & \multicolumn{3}{|l|}{ DA-APCl } & \multicolumn{3}{|l|}{ DA-APPI } \\
\hline & & $\mathrm{M}^{+}$ & {$[\mathrm{M}+\mathrm{H}]^{+}$} & $\begin{array}{l}\text { Fragments and } \\
\text { adducts }\end{array}$ & $M^{+}$ & {$[\mathrm{M}+\mathrm{H}]^{+*}$} & Fragments and adducts & $M^{+}$ & $\begin{array}{l}{[\mathrm{M}+\mathrm{H}]^{+}} \\
*\end{array}$ & Fragments and adducts \\
\hline apomorphine & 267.1 & & $268(100)$ & & $267(11)$ & $268(100)$ & & $267(17)$ & $\begin{array}{l}268 \\
(100)\end{array}$ & \\
\hline $\mathrm{B}[\mathrm{a}] \mathrm{P}$ & 252.1 & & $253(100)$ & & 252 (18) & $253(100)$ & & $252(61)$ & $\begin{array}{l}253 \\
(100)\end{array}$ & \\
\hline BPA & 228.1 & & & $\begin{array}{l}135(100,[\mathrm{MH}- \\
\left.\left.\mathrm{C}_{6} \mathrm{H}_{5} \mathrm{OH}\right]^{+}\right)\end{array}$ & $228(39)$ & & $\begin{array}{l}135\left(65,\left[\mathrm{MH}-\mathrm{C}_{6} \mathrm{H}_{5} \mathrm{OH}\right]^{+}\right) \\
213\left(100,\left[\mathrm{M}-\mathrm{CH}_{3}\right]^{+}\right)\end{array}$ & $228(39)$ & & $\begin{array}{l}135\left(26,\left[\mathrm{MH}-\mathrm{C}_{6} \mathrm{H}_{5} \mathrm{OH}\right]^{+}\right) \\
213\left(100,\left[\mathrm{M}-\mathrm{CH}_{3}\right]^{+}\right)\end{array}$ \\
\hline $\begin{array}{l}\text { ceramide } \\
\text { C12 }\end{array}$ & 481.4 & & & $\begin{array}{l}200(13,[\mathrm{MH}- \\
\left.\left.\mathrm{C}_{18} \mathrm{H}_{34} \mathrm{O}_{2}\right]^{+}\right) \\
464\left(100,\left[\mathrm{MH}-\mathrm{H}_{2} \mathrm{O}\right]^{+}\right)\end{array}$ & & & $\begin{array}{l}200\left(13,\left[\mathrm{MH}-\mathrm{C}_{18} \mathrm{H}_{34} \mathrm{O}_{2}\right]^{+}\right) \\
464\left(100,\left[\mathrm{MH}-\mathrm{H}_{2} \mathrm{O}\right]^{+}\right)\end{array}$ & & & $\begin{array}{l}200(11,[\mathrm{MH}- \\
\left.\left.\mathrm{C}_{18} \mathrm{H}_{34} \mathrm{O}_{2}\right]^{+}\right) \\
464\left(100,\left[\mathrm{MH}-\mathrm{H}_{2} \mathrm{O}\right]^{+}\right)\end{array}$ \\
\hline cholesterol & 386.4 & & & $369\left(100,\left[\mathrm{MH}-\mathrm{H}_{2} \mathrm{O}\right]^{+}\right)$ & & & $369\left(100,\left[\mathrm{MH}-\mathrm{H}_{2} \mathrm{O}\right]^{+}\right)$ & & & $369\left(100,\left[\mathrm{MH}-\mathrm{H}_{2} \mathrm{O}\right]^{+}\right)$ \\
\hline DT & 290.2 & & $291(23 *)$ & $\begin{array}{l}255\left(32,\left[\mathrm{MH}-2 \mathrm{H}_{2} \mathrm{O}\right]^{+}\right) \\
257(12) \\
271(13) \\
273\left(100,\left[\mathrm{MH}-\mathrm{H}_{2} \mathrm{O}\right]^{+}\right) \\
285(10) \\
287\left(39,[\mathrm{M}-3]^{+}\right) \\
289\left(94,[\mathrm{M}-\mathrm{H}]^{+}\right) \\
305\left(28,[\mathrm{M}+15]^{+}\right)\end{array}$ & & $291(31)$ & $\begin{array}{l}255\left(31,\left[\mathrm{M} \mathrm{H}-2 \mathrm{H}_{2} \mathrm{O}\right]^{+}\right) \\
257(15) \\
271(13) \\
272(17) \\
273\left(100,\left[\mathrm{MH}-\mathrm{H}_{2} \mathrm{O}\right]^{+}\right) \\
287\left(37,[\mathrm{M}-3]^{+}\right) \\
289\left(100,[\mathrm{M}-\mathrm{H}]^{+}\right) \\
305\left(38,[\mathrm{M}+15]^{+}\right)\end{array}$ & & $\begin{array}{l}291 \\
(23)\end{array}$ & $\begin{array}{l}255\left(30,\left[\mathrm{MH}-2 \mathrm{H}_{2} \mathrm{O}\right]^{+}\right) \\
271(11) \\
273\left(92,\left[\mathrm{MH}-\mathrm{H}_{2} \mathrm{O}\right]^{+}\right) \\
285(15) \\
287\left(48,[\mathrm{M}-3]^{+}\right) \\
289\left(100,[\mathrm{M}-\mathrm{H}]^{+}\right) \\
305\left(48,[\mathrm{M}+15]^{+}\right)\end{array}$ \\
\hline E2 & 272.2 & & & $255\left(100,\left[\mathrm{MH}-\mathrm{H}_{2} \mathrm{O}\right]^{+}\right)$ & $272(29)$ & & $255\left(100,\left[\mathrm{MH}-\mathrm{H}_{2} \mathrm{O}\right]^{+}\right)$ & $272\left(74^{*}\right)$ & & $\begin{array}{l}255\left(100,\left[\mathrm{MH}-\mathrm{H}_{2} \mathrm{O}\right]^{+}\right) \\
271\left(10,[\mathrm{M}-\mathrm{H}]^{+}\right)\end{array}$ \\
\hline luteolin & 286.0 & & $287(100)$ & & & $287(100)$ & & $286(13)$ & $\begin{array}{l}287 \\
(100) \\
\end{array}$ & \\
\hline nonylphenol & 220.2 & & & & $\begin{array}{l}220 \\
(100)\end{array}$ & & & $\begin{array}{l}220 \\
(100)\end{array}$ & & \\
\hline $\begin{array}{l}\text { sulindac } \\
\text { sulfide }\end{array}$ & 340.1 & & $341(100)$ & $\begin{array}{l}295\left(17,\left[\mathrm{MH}-\mathrm{H}_{2} \mathrm{O}-\right.\right. \\
\left.\mathrm{CO}^{+}\right) \\
297\left(22,\left[\mathrm{MH}^{-} \mathrm{CO}_{2}\right]^{+}\right) \\
311(18)\end{array}$ & $340(42)$ & $341(100)$ & $\begin{array}{l}293(10) \\
295\left(18,\left[\mathrm{MH}-\mathrm{H}_{2} \mathrm{O}-\mathrm{CO}\right]^{+}\right) \\
296(12) \\
297\left(18,\left[\mathrm{MH}-\mathrm{CO}_{2}\right]^{+}\right)\end{array}$ & $\begin{array}{l}340 \\
(100)\end{array}$ & $\begin{array}{l}341 \\
(85)\end{array}$ & $\begin{array}{l}295\left(19,\left[\mathrm{MH}-\mathrm{H}_{2} \mathrm{O}-\mathrm{CO}\right]^{+}\right) \\
296(25) \\
297(16) \\
311(14)\end{array}$ \\
\hline
\end{tabular}




\begin{tabular}{|c|c|c|c|c|c|c|c|c|c|}
\hline & & & $355\left(33,[M+15]^{+}\right)$ & & & \begin{tabular}{|l|}
$311(16)$ \\
$313(10)$ \\
$355\left(29,[M+15]^{+}\right)$
\end{tabular} & & & $355\left(15,[M+15]^{+}\right)$ \\
\hline squalene & 410.4 & $411(100)$ & $\begin{array}{l}261(14) \\
329(13)\end{array}$ & $410(15)$ & $411(100)$ & $\begin{array}{l}261(14) \\
329(14) \\
341\left(15,\left[\mathrm{M}-\mathrm{C}_{5} \mathrm{H}_{9}\right]^{+}\right)\end{array}$ & $410(59)$ & $\begin{array}{l}411 \\
(100)\end{array}$ & $\begin{array}{l}261(15) \\
329(15) \\
341\left(38,\left[\mathrm{M}-\mathrm{C}_{5} \mathrm{H}_{9}\right]^{+}\right) \\
367\left(13,\left[\mathrm{MH}-\mathrm{C}_{3} \mathrm{H}_{8}\right]^{+}\right)\end{array}$ \\
\hline$T$ & 288.2 & $289(100)$ & \begin{tabular}{|l|}
$285\left(10,[\mathrm{M}-3]^{+}\right)$ \\
$287\left(35,[\mathrm{M}-\mathrm{H}]^{+}\right)$ \\
\end{tabular} & & $289(100)$ & $287\left(34,[\mathrm{M}-\mathrm{H}]^{+}\right)$ & & $\begin{array}{l}289 \\
(100)\end{array}$ & $287\left(47,[\mathrm{M}-\mathrm{H}]^{+}\right)$ \\
\hline tonalide & 258.2 & $259(100)$ & & & $259(100)$ & $243\left(11,\left[\mathrm{M}-\mathrm{CH}_{3}\right]^{+}\right)$ & & $\begin{array}{l}259 \\
(100)\end{array}$ & $243\left(12,\left[\mathrm{M}-\mathrm{CH}_{3}\right]^{+}\right)$ \\
\hline verapamil & 454.3 & $455(100)$ & & & $455(100)$ & & & $\begin{array}{l}455 \\
(100)\end{array}$ & $303(17)$ \\
\hline \multicolumn{2}{|l|}{ PAH mix } & \multicolumn{2}{|c|}{$\begin{array}{l}179(7), 203(4), 229(8), 253(100), 277 \\
(48), 279(7)\end{array}$} & \multicolumn{3}{|c|}{$\begin{array}{l}152(10), 154(14), 166(13), 178(31), 179\left(7^{*}\right) \\
202(28), 203(4 *), 228(31), 229\left(8^{*}\right), 252(47), \\
253(100), 276(34), 277\left(47^{*}\right), 278\left(15^{*}\right), 279(4 *)\end{array}$} & \multicolumn{3}{|c|}{$\begin{array}{l}128(10), 152(22), 166(30), 178(82), 202 \\
(66), 228(63), 252(100), 253\left(60^{*}\right), 276(75), \\
277(22 *), 278(32 *)\end{array}$} \\
\hline
\end{tabular}



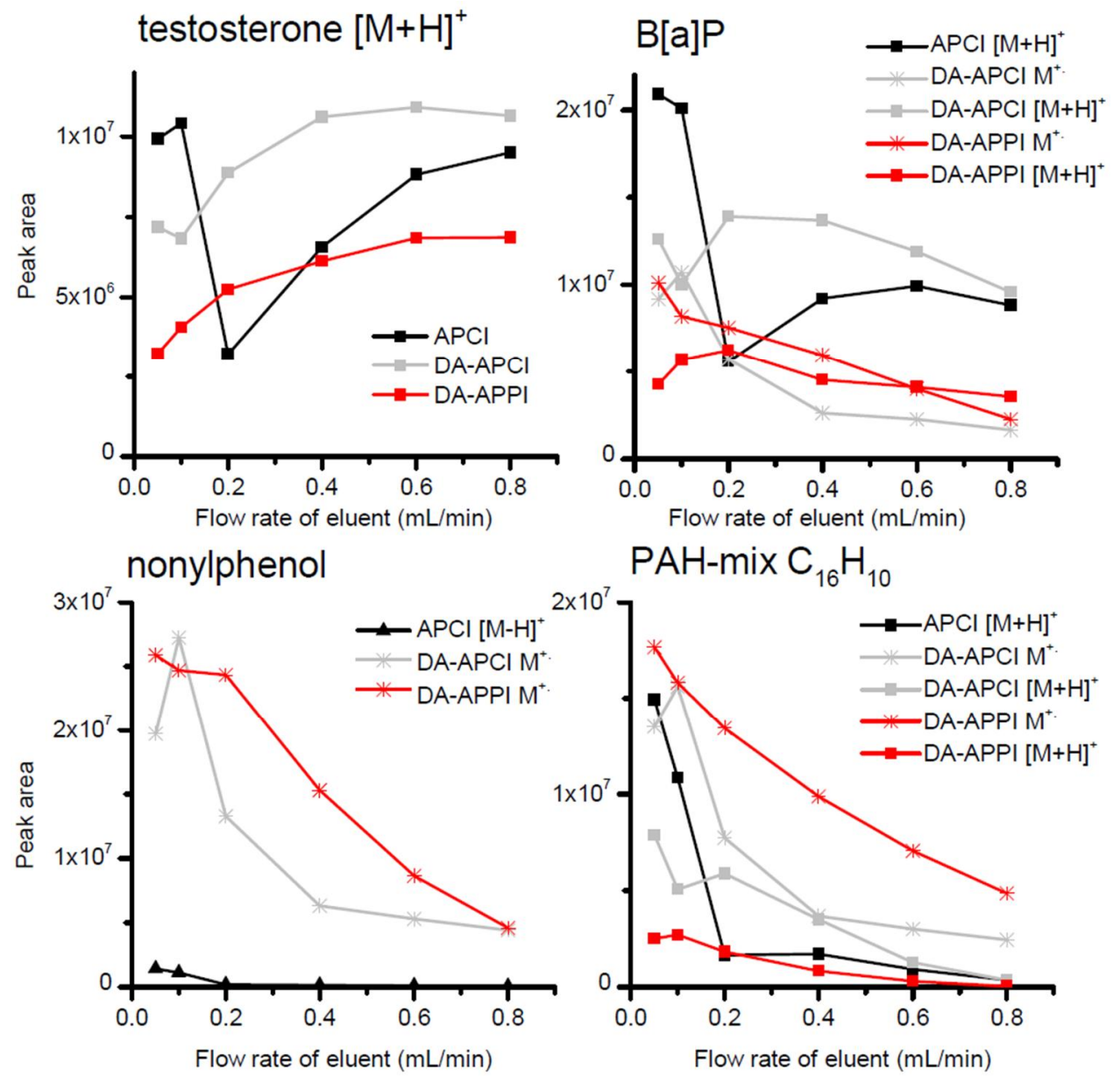

Figure 1: Peak areas for selected analyte ions as a function of flow rate in APCl (without dopant), dopantassisted APCI (DA-APCI) and dopant-assisted APPI (DA-APPI). Dopant flow rate was $10 \%$ of the eluent flow rate in dopant-assisted $\mathrm{APCl}$ and $\mathrm{APPI}$. The areas for $[\mathrm{M}+\mathrm{H}]^{+}$ion of $\mathrm{B}[\mathrm{a}] \mathrm{P}$ and $\mathrm{C}_{16} \mathrm{H}_{10} \mathrm{PAH}$ were obtained by deducing the natural abundance of the ${ }^{13} \mathrm{C}$ isotope of the respective $\mathrm{M}^{+}$ion.

\section{Reagent ions}

To better understand the effect of the flow rate on the ionization of the analytes, the formation of reagent ions from eluent and dopant was investigated (Figure 2). Since the experiments were conducted on a MS instrument with an atmospheric pressure interface that was not specifically designed for measuring clusters, we were not able to measure the true solvent cluster ion distribution in the source [31]. This is because the clusters dissociate before detection due to high electric fields in the ion optics. Furthermore, atmospheric pressure ion sources discriminate transmission of smaller ions ( $\mathrm{m} / \mathrm{z}<$ about $40-80)$. However, the study design allowed monitoring changes in the dopant derived reagent ions that are especially interesting when trying to understand the charge exchange reaction between the dopant and the analytes. 
The reagent ion populations with $\mathrm{APCl}, \mathrm{DA}-\mathrm{APCl}$ and $\mathrm{DA}-\mathrm{APPI}$ were very different. In APCl, methanol [M $+\mathrm{H}]^{+}$ and $[2 \mathrm{M}+\mathrm{H}]^{+}$ions were observed together with unidentified ions, that most likely originate from impurities or residues in used gases, solvents, laboratory air, and equipment. In DA-APCl, the radical cation of chlorobenzene (m/z 112) was observed at all studied flow rates, but its absolute abundance decreased dramatically as the flow rate increased. On the other hand, the relative abundances of ions at $\mathrm{m} / \mathrm{z} 108$ and 128 grew as the flow rate increased. MS/MS-measurement of the m/z 108 ion and anisole standard showed that in DA-APCl the ion at $\mathrm{m} / \mathrm{z} 108$ is a mixture: $\mathrm{M}^{+}$of anisole was the main species and an unidentified component gave a minor signal (see Supplementary Material, Figure S4). In DA-APPI, the chlorobenzene radical cation appeared as the most abundant solvent ion at 0.05 and $0.1 \mathrm{~mL} / \mathrm{min}$ flow rate, but an ion at $\mathrm{m} / \mathrm{z}$ 108 was the most prominent at higher flow rates. Robb et al. have also reported the $\mathrm{m} / \mathrm{z} 108$ reagent ion for chlorobenzene in DA-APPI-MS under slightly different experimental conditions [12]. Here, MS/MS measurement showed that the fragmentation of the $\mathrm{m} / \mathrm{z} 108$ ion is identical to that of $\mathrm{M}^{+}$. ion of anisole (Supplementary Material Figure S4). The abundance of reagent ions at 0.2-0.6 mL flow rates was higher in DA-APPI compared to DA-APCl, and this was mainly due to the $\mathrm{m} / \mathrm{z} 108$ ion.
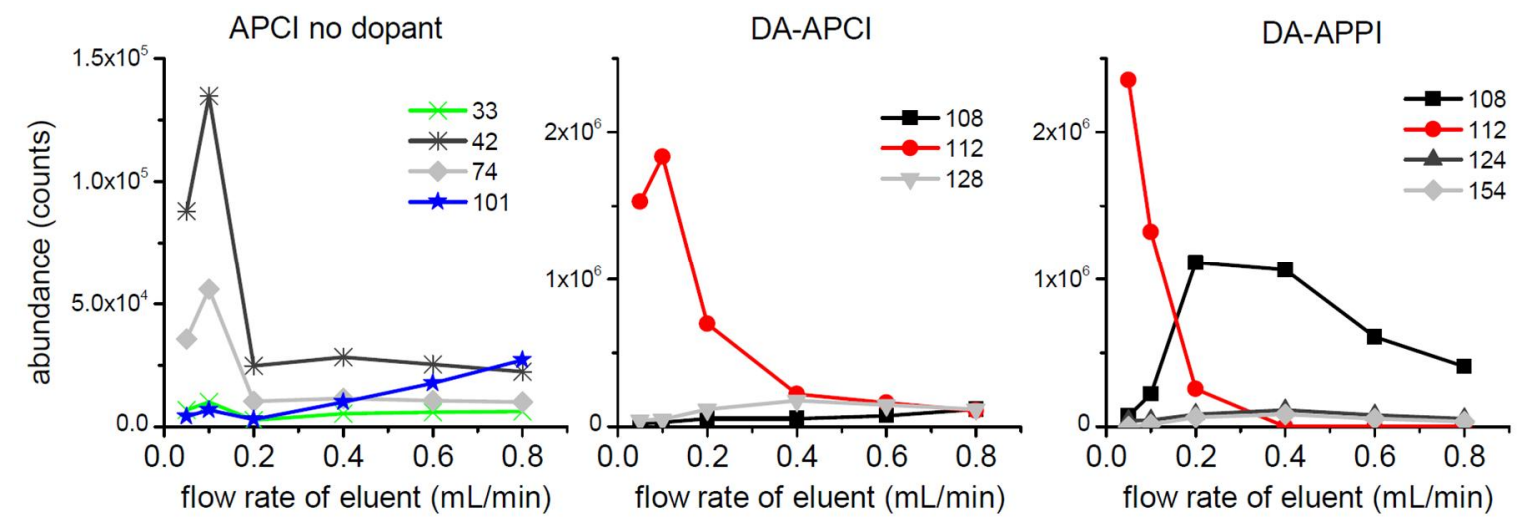

Figure 2. Abundance of the most intense reagent ions as function of eluent ( $\left.\mathrm{MeOH}: \mathrm{H}_{2} \mathrm{O}(80: 20)\right)$ flow rate in APCl (without dopant), dopant-assisted APCI (DA-APCI) and dopant-assisted APPI (DA-APPI). Note that the results for $\mathrm{APCl}$ and the dopant-assisted techniques are presented on different scales. 


\section{Discussion}

\section{Ionization of model compounds in APCI}

14 individual compounds and a commercial mix of PAHs were chosen as model analytes for the study. The analytes included mid- to nonpolar compounds with reported or estimated IE:s ranging from 6.1 to $10.2 \mathrm{eV}$ and PAs from 803 to $980 \mathrm{~kJ} / \mathrm{mol}$ (Table 2, 3). APCl (without a dopant) was suited for the ionization of most of the model compounds selected for the study: only nonylphenol and C10-C13 PAHs gave extremely low signals at the used experimental conditions. Proton transfer was clearly the main ionization route in APCl, and in the case of ceramide C12, cholesterol, DT, and E2, it was associated with the loss of water from the protonated analyte. This and the absence of analyte radical cations in the spectra show that our measurements are in agreement with the generally accepted ionization mechanism of $\mathrm{APCl}$ [9], where the corona discharge ionizes nitrogen, leading to the formation of protonated eluent clusters that protonate the analytes (Reactions 1-6, Table 1).

\section{Ionization of model compounds in DA-APCI}

Based on previous results from Song et al. [16] and Perazzolli et al. [15], it was expected that analyte radical cations could be formed in DA-APCI with chlorobenzene as the dopant. If the ionization mechanism is charge exchange between the dopant and the analyte as suggested for benzene dopant by Perazzolli et al. [15] (Table 1, Reaction 7), the compounds that have lower IE than the chlorobenzene dopant (9.1 eV [14]) should be ionized by charge exchange in DA-APCI. Indeed, ceramide C12, DT, T, tonalide, and verapamil, which have reported or estimated IEs above the IE of chlorobenzene (Table 2) were protonated, but did not show radical cations in DA-APCl. On the other hand, all compounds with IEs below the IE of chlorobenzene, except cholesterol, were ionized at least to some extent by charge exchange (Table 4, Figure 1 and S2). Charge exchange was the main ionization reaction in DA-APCl in the case of nonylphenol, BPA (assuming $\left[\mathrm{M}-\mathrm{CH}_{3}\right]^{+}$ ion at $\mathrm{m} / \mathrm{z} 213$ derives from the radical cation), and fluorene in the PAH mix, and somewhat equally efficient with proton transfer for the other compounds of the PAH mix. For the rest of the analytes (apomorphine, $B[a] P, E 2$, luteolin, sulindac sulfide, squalene), the efficiency of charge exchange was low compared to the efficiency of proton transfer at typical APCl flow rates $(0.2-0.8 \mathrm{~mL} / \mathrm{min})$. Thus at DA-APCl, there are two main reaction pathways, namely charge exchange and proton transfer, and their relative efficiency depends on 
the flow rate of the eluent as shown in Figures 1 and $\mathrm{S} 2$ in Supplementary Material and discussed below. The measurement of the solvent reagent ions shows that analyte radicals may be formed in charge exchange with dopant radicals, but additionally, anisole radical cation and an unidentified reagent ion at $\mathrm{m} / \mathrm{z} 128$ may also be involved in the ionization reactions. The IE of anisole is $8.2 \mathrm{eV}$ [14], so it is able to react by charge exchange with most of the analytes showing radical cations in this study (Tables 2-4).

The addition of chlorobenzene dopant to the eluent flow in APCI had a significant effect on the ionization of several of the analytes. Most importantly, nonylphenol and fluorene (PAH mix) showed extremely small signals in APCl, but were efficiently ionized in DA-APCl via charge exchange. As can be seen from Tables 2 and 3, the estimated or previously reported PAs for nonylphenol and fluorene are amongst the lowest for the chosen model analytes. Thus, it can be concluded, that the use of a dopant extends the application range of APCl toward low PA compounds. Secondly, C14-C18 PAHs in the PAH mix were observed as protonated molecules in APCl without a dopant, but showed radical cations as main ions in DA-APCI. This resulted in better sensitivity, especially at flow rate $0.2 \mathrm{~mL} / \mathrm{min}$ and above (Figure 1 and S2 in Supplementary Material). Again deriving from the gas-phase properties of the compounds, this shows that DA-APCI can provide better ionization efficiency for low PA, low IE compounds by the alternative charge exchange ionization mechanism.

\section{Ionization of model compounds in DA-APPI}

The analyte ions observed with DA-APPI were very similar to those in DA-APCI (Table 4). Radical cation formation in DA-APPI is typically explained by photon induced ionization of the dopant (Table 1, Reaction A), and subsequent charge exchange reaction between the dopant radical cation and the analytes (Table 1 , Reaction F). As expected, ionization by charge exchange in DA-APPI occurred to compounds with IEs (Table 2 , 3) below the IE of the dopant $(9.1 \mathrm{eV})$ with the exception of cholesterol, which showed the $\left[\mathrm{MH}-\mathrm{H}_{2} \mathrm{O}\right]^{+}$ion. Nevertheless, when the solvent ions are considered, the absence of chlorobenzene radical at eluent flow rate $0.4 \mathrm{~mL} / \mathrm{min}$ and higher, and the high abundance of the radical cation of anisole at $\mathrm{m} / \mathrm{z} 108$ in the DA-APPI solvent spectra indicate that besides direct dopant radical cation-analyte neutral interactions, more complicated reaction routes are likely to be involved. Since anisole has IE of $8.2 \mathrm{eV}$, its radical cation may also react with the analytes, and therefore contribute to the ionization process in DA-APPI. 
Proton transfer was observed also in DA-APPI, although the radical cation of the chlorobenzene dopant is not likely to transfer a proton to analyte molecules, and the photon energy in APPI (10.0 and $10.6 \mathrm{eV}$ ) is not sufficient to ionize water (IE $=12.6 \mathrm{eV}[14])$ or methanol (IE $=10.8 \mathrm{eV}[14])$ molecules. As discussed earlier in literature [31, 32], water and solvent clusters must thus take part in the ionization process. Water and methanol clusters have sufficiently low IEs $[33,34]$ to be ionized by the 10.0 and $10.6 \mathrm{eV}$ photons, and subsequent self-protonation can lead to generation of protonated solvent clusters. Alternatively, neutral solvent molecules can associate with dopant radical cations, and this also leads to generation of protonated solvent clusters [31]. The protonated solvent clusters can thereby protonate the analytes (Table 1, Reaction D), possibly by ligand-switching as suggested by Klee et al. [31].

\section{Effect of flow rate}

In $\mathrm{DA}-\mathrm{APCl}$, the most favorable experimental conditions for charge exchange were reached at $0.1 \mathrm{~mL} / \mathrm{min}$ flow rate (Figure 1 and S2 in Supplementary M aterial). Both the absolute peak areas of the radical cations and the relative abundance compared to $[\mathrm{M} \mathrm{H}]^{+}$or $\left[\mathrm{MH}-\mathrm{H}_{2} \mathrm{O}\right]^{+}$ions reached maxima, and decreased as the flow rate was increased. Also the abundance of the radical cation of chlorobenzene had a maximum at 0.1 $\mathrm{mL} / \mathrm{min}$ flow rate, and it decreased as the flow rate was increased (Figure 2). Overall, the abundance of the dopant radical cation followed closely the peak area trend of the analyte radical cations. This is similar to results obtained for DA-APPI here and in literature [28]. It has been suggested that impurities in the solvent start to dominate the ionization in APPI when the flow rate is increased, and this would lead to suppression of ionization of analytes [28, 35]. The solvent spectra in DA-APCl show the appearance of reagent ions at $\mathrm{m} / \mathrm{z}$ 108 and 128 with increasing flow rate (Figure 2), but besides impurities, the ions could also derive from gasphase reactions of the dopant. Another possible explanation for the decreased signals at increased flow rate could be a change in cluster size distribution: the PAs of water and methanol clusters increase with increasing cluster size [36], and IEs of methanol clusters are also smaller than for the free molecule [33, 34]. Because the clusters shift to larger sizes with increasing flow rate, the clusters will effectively neutralize the dopant radical cations, and disappearance of the dopant radical cation thus prevents the charge exchange between the dopant and the analytes. Reactions of dopant radical cations via charge exchange with solvent clusters 
are unlikely, since the IEs of methanol clusters $(n<9)$ are above the IE of chlorobenzene. Additionally, it is possible that the increased density of solvent in the source at high flow rates increases the probability of depletion of both dopant and analyte radical cations by neutralization and other reactions before they are admitted to the MS. This is supported by a study of Lorenz et al. [37], which showed that in atmospheric pressure source, radical cations are depleted quicker than protonated molecules, and the survival of radical cations from the site of ionization to the MS depends e.g. on the amount of oxygen in the ion source.

Interestingly, low flow rates $(0.05-0.1 \mathrm{~mL} / \mathrm{min})$ were also extremely feasible for proton transfer in $\mathrm{APCl}$ in the case of C14-C22 PAHs of the PAH mix (Figure S2 in Supplementary Material). These analytes formed mainly radical cations in $\mathrm{DA}-\mathrm{APCl}$, but protonated molecules in $\mathrm{APCl}$. The result is in agreement with previous reports using $\mathrm{APCl}$, which have shown signal decrease at high flow rates, especially for lower polarity compounds $[38,39]$. The flow rate dependence in APCI could be explained by the growth of eluent cluster size, which reduces proton transfer between protonated eluent clusters and analytes with low PA. Also, an increased amount of solvent impurities in the source may lead to competition for protons between analytes and the impurities, and decrease the ionization efficiency of the analytes.

\section{Comparison of charge exchange efficiency in DA-APCI and DA-APPI}

Relative efficiency of charge exchange compared to proton transfer was greater in DA-APPI than in DA-APCI at all studied flow rates $\left(\mathrm{A}\left(\mathrm{M}^{+}\right) / \mathrm{A}\left([\mathrm{M}+\mathrm{H}]^{+}\right)\right.$or $\mathrm{A}\left(\mathrm{M}^{+}\right) / \mathrm{A}\left(\left[\mathrm{M} \mathrm{H}-\mathrm{H}_{2} \mathrm{O}\right]^{+}\right)$values being 1.1-84 fold (median 4.0) in APPI compared to APCl, see Figure 1 and S2 in Supplementary Material). Comparison of peak areas in DAAPCI and DA-APPI shows that the absolute charge exchange efficiency was similar or larger in DA-APPI compared to DA-APCl at 0.05 and $0.2-0.6 \mathrm{~mL} / \mathrm{min}$, while DA-APCI was slightly better or somewhat equal to DA-APPI at $0.1 \mathrm{~mL} / \mathrm{min}$ flow rate depending on the analyte. The difference between the techniques was generally small, but at $0.2-0.6 \mathrm{~mL} / \mathrm{min}$ flow rate area DA-APPI was more efficient for low IE, low PA compounds that are poorly ionized by proton transfer, as peak areas for radical cations were even 3-fold compared to those in DA-APCI (Figure 1 and S2 in Supplementary Material).

The higher charge exchange to proton transfer efficiency in DA-APPI is expected to derive from the equilibrium of the two competing reaction pathways. The restricted photon energy in DA-APPI does not allow 
the efficient ionization of eluent molecules and small eluent clusters mainly responsible for protonation of analytes, and favors the formation of dopant $\mathrm{M}^{+}$ion, which is the main charge exchange reagent in the solvent system. Also, self-protonation of dopant or generation of protonated solvent clusters via interaction between dopant radical cation and neutral solvent clusters [31] are not able to efficiently generate protonated reagents, and proton transfer between dopant radical cation and analytes is expected to be negligible. On the other hand, in DA-APCI the generation of both protonated eluent clusters and dopant radical cations is feasible. This rationale would indicate higher relative amount of the protonating eluent ions in DA-APCl compared to DA-APPI, which would in turn favor proton transfer of the analytes as observed in our measurements. This would also mean that charge exchange efficiency in DA-APCl could be increased by increasing the flow rate of the dopant, since it would increase the amount of charge exchange reagent ions compared to the protonating species favoring charge exchange ionization of analytes. This is supported by measurement of DA-APCl spectra at constant eluent flow rate of $0.8 \mathrm{~mL} / \mathrm{min}$ and varying dopant flow rate $(0-20 \%$ of the flow rate of the eluent, Figure S3 in Supplementary M aterial) as peak areas of radical cations increased somewhat linearly as the flow rate of the dopant was increased while peak areas for analyte $[\mathrm{M}+\mathrm{H}]^{+}$ remained almost constant.

Comparison of the solvent ions in DA-APPI and DA-APCI suggests that there are also differences between charge exchange reaction routes (Figure 2). Chlorobenzene radicals decreased rapidly when the flow rate was increased and were absent at high flow rates $(0.4-0.8 \mathrm{~mL} / \mathrm{min})$ in the DA-APPI spectra, whereas $\mathrm{m} / \mathrm{z} 108$ ion (anisole $\mathrm{M}^{+}$) showed a high signal, roughly an order of magnitude higher than in DA-APCI. In DA-APCl, low, somewhat equal abundances were observed for chlorobenzene and anisole radicals, and the unidentified ion at $\mathrm{m} / \mathrm{z} 128$. This may be important for the charge exchange ionization of the analytes in DAAPPI, since the higher production of the anisole radical cation in DA-APPI coincides with higher analyte radical cation production compared to DA-APCI (Figure 2). Since anisole has IE of $8.2 \mathrm{eV}$, it is possible that it reacts with the analytes. 
Robb et al. [12] previously suggested that in DA-APPI the $\mathrm{m} / \mathrm{z} 108$ ion (anisole) is formed in a substitution reaction between neutral methanol and chlorobenzene radical cation following a general reaction scheme for several halobenzenes:

$D^{+}+n S \rightarrow P^{+}+n H X$

where $P$ is the product (here anisole) and $X$ the halogen. If the reaction occurred according to reaction 1 in our experiments, we would expect observing similar relative abundance of the chlorobenzene radical cation $(\mathrm{m} / \mathrm{z} 112)$ and the anisole radical cation $(\mathrm{m} / \mathrm{z} 108)$ in both DA-APCI and DA-APPI at the same experimental conditions. However, in DA-APCI the relative abundance of anisole radical cation was much lower than in DAAPPI. To explain the observed results, we hypothesize that the $\mathrm{m} / \mathrm{z} 108$ ion derives from a reaction between neutral methanol radical and the dopant:

$$
\begin{aligned}
& \mathrm{CH}_{3} \mathrm{OH}+h v \rightarrow \mathrm{CH}_{3} \mathrm{O}+\mathrm{H} \cdot \quad\left(\mathrm{DH}=4.5 \mathrm{eV}[40]<h v=10.0 \text { and } 10.6 \mathrm{eV}<\mathrm{IE}\left(\mathrm{CH}_{3} \mathrm{OH}\right)=10.8 \mathrm{eV}[14]\right) \\
& \mathrm{CH}_{3} \mathrm{O}+\mathrm{C}_{6} \mathrm{H}_{5} \mathrm{Cl} \rightarrow \mathrm{C}_{6} \mathrm{H}_{5} \mathrm{OCH}_{3}+\mathrm{Cl} \quad(\Delta \mathrm{H}=-18.8 \mathrm{~kJ} / \mathrm{mol} \text {, see Supplementary M aterial })
\end{aligned}
$$

Since the UV radiation in APPI is not sufficiently energetic to ionize methanol molecules, but the methanol $\mathrm{OH}$ bond dissociation energy is lower, $4.5 \mathrm{eV}$ [40], photolysis is a likely result of photon absorption by methanol. Formation of neutral radicals in APPI has been shown previously for $\mathrm{O}_{2}$ and $\mathrm{H}_{2} \mathrm{O}$ [41]. Different solvent ion compositions in DA-APPI and DA-APCl are thus suggested to reflect also neutral radical compositions of the ion sources and derive from the different energy distributions of primary ionizing species (photons versus corona discharge).

\section{Conclusions}

In this work, we sought to elaborate differences between dopant-assisted APCI and dopant-assisted APPI. Chlorobenzene was chosen as the dopant due to its previous success in DA-APPI. Both proton transfer and charge exchange occurred in dopant-assisted APCI and APPI, and the studied analytes formed mainly the same ions in both techniques. The charge exchange efficiencies of the techniques were found somewhat similar, although DA-APPI was slightly more efficient at typical LC flow rates $(0.2-0.6 \mathrm{ml} / \mathrm{min})$ compared to DA-APCI. Thus, both techniques can be used for compounds that cannot be ionized by proton transfer in APCI without a dopant, and the results encourage the use of dopant-assisted APCI instead of APPI if both charge 
exchange and proton transfer chemistry is needed for ionization of target analytes. We can also recommend the use of low flow rates $(0.1 \mathrm{~mL} / \mathrm{min}$ or lower) to favor ionization by charge exchange. While the results for the analytes were closely similar, the two techniques showed different solvent ions indicating different side reactions affecting the pathway of analyte radical cation formation.

\section{Acknowledgements}

The authors acknowledge Academy of Finland for financial support (grant numbers 218150, 125758, 255559, 275089, and 251575).

\section{References}

1. Carroll, D.I., Dzidic, I., Stillwell, R.N., Haegele, K.D., Horning, E.C.: Atmospheric pressure ionization mass spectrometry. Corona discharge ion source for use in a liquid chromatograph-mass spectrometercomputer analytical system. Anal. Chem. 47, 2369-2373 (1975).

2. Horning, E.C., Horning, M.G., Carroll, D.I., Dzidic, I., Stillwell, R.N.: New picogram detection system based on a mass spectrometer with an external ionization source at atmospheric pressure. Anal. Chem. 45, 936-943 (1973).

3. Hunt, D.F., M cEwen, C.N., Harvey, T.M.: Positive and negative chemical ionization mass spectrometry using a Townsend discharge ion source. Anal. Chem. 47, 1730-1734 (1975).

4. Kauppila, T.J., Syage, J.A., Benter, T.: Recent developments in atmospheric pressure photoionizationmass spectrometry. M ass Spectrom. Rev. 9999, 1-27 (2015).

5. Ghislain, T., Faure, P., M ichels, R.: Detection and M onitoring of PAH and Oxy-PAHs by High Resolution Mass Spectrometry: Comparison of ESI, APCl and APPI Source Detection. J. Am. Soc. Mass Spectrom. $23,530-536(2012)$.

6. Rhourri-Frih, B., Chaimbault, P., Claude, B., Lamy, C., André, P., Lafosse, M.: Analysis of pentacyclic triterpenes by LC-MS. A comparative study between APCI and APPI. J M ass Spectrom. 44, 71-80 (2009).

7. Wang, C., Gardinali, P.R.: Comparison of multiple API techniques for the simultaneous detection of microconstituents in water by on-line SPE-LC-M S/M S. J M ass Spectrom. 47, 1255- 1268 (2012). 
8. Yang, C., Henion, J.: Atmospheric pressure photoionization liquid chromatographic-mass spectrometric determination of idoxifene and its metabolites in human plasma. J. Chromatogr. A. 970, 155-165 (2002).

9. Carroll, D.I., Dzidic, I., Horning, E.C., Stillwell, R.N.: Atmospheric Pressure lonization Mass Spectrometry. Appl. Spectrosc. Rev. 17, 337-406 (1981).

10. Good, A., Durden, D.A., Kebarle, P.: Ion-Molecule Reactions in Pure Nitrogen and Nitrogen Containing Traces of Water at Total Pressures 0.5-4 torr. Kinetics of Clustering Reactions Forming $\mathrm{H}^{+}\left(\mathrm{H}_{2} \mathrm{O}\right)_{n}$. J. Chem. Phys. 52, 212-221 (1970).

11. Kauppila, T.J., Kostiainen, R., Bruins, A.P.: Anisole, a new dopant for atmospheric pressure photoionization mass spectrometry of low proton affinity, low ionization energy compounds. Rapid Commun. M ass Spectrom. 18, 808-815 (2004).

12. Robb, D.B., Smith, D.R., Blades, M.W.: Investigation of Substituted-Benzene Dopants for Charge Exchange Ionization of Nonpolar Compounds by Atmospheric Pressure Photoionization. J. Am. Soc. Mass Spectrom. 19, 955-963 (2008).

13. Smith, D.R., Robb, D.B., Blades, M.W.: Comparison of dopants for charge exchange ionization of nonpolar polycyclic aromatic hydrocarbons with reversed-phase LC-APPI-MS. J. Am. Soc. Mass Spectrom. 20, 73-79 (2011).

14. NIST Chemistry WebBook, NIST Standard Reference Database Number 69. Eds. P.J. Linstrom and W.G. Mallard, National Institute of Standards and Technology, Gaithersburg MD, 20899, http://webbook.nist.gov, (retrieved October 20, 2015)

15. Perazzolli, C., Mancini, I., Guella, G.: Benzene-assisted atmospheric-pressure chemical ionization: a new liquid chromatography/mass spectrometry approach to the analysis of selected hydrophobic compounds. Rapid Commun. Mass Spectrom. 19, 461-469 (2005).

16. Song, L., Cho, D.S., Bhandari, D., Gibson, S.C., McNally, M.E., Hoffman, R.M., Cook, K.D.: Liquid chromatography/dopant-assisted atmospheric pressure chemical ionization mass spectrometry for the analysis of non-polar compounds. Int. J. Mass Spectrom. 303, 173-180 (2011). 
17. Kostiainen, R., Kauppila, T.J.: Effect of eluent on the ionization process in liquid chromatography-mass spectrometry. J. Chromatogr. A. 1216, 685-699 (2009).

18. Chiaia-Hernandez, A.C., Krauss, M., Hollender, J.: Screening of Lake Sediments for Emerging Contaminants by Liquid Chromatography Atmospheric Pressure Photoionization and Electrospray Ionization Coupled to High Resolution Mass Spectrometry. Environ. Sci. Technol. 47, 976-986 (2013).

19. Vendrame, R., Ferreira, M.M.C., Collins, C.H., Takahata, Y.: Structure-activity relationships (SAR) of contraceptive progestogens studied with four different methods using calculated physicochemical parameters. J. Mol. Graph. M odel. 20, 345-358 (2002).

20. Novak, I., Kovač, B.: Electronic structure and biological activity of steroids. Biophys. Chem. 78, 233-240 (1999).

21. Lei, H., Snyder, S.A.: 3D QSPR models for the removal of trace organic contaminants by ozone and free chlorine. Water Res. 41, 4051-4060 (2007).

22. Aue, D.H., Guidoni, M., Betowski, L.D.: Ab initio calculated gas-phase basicities of polynuclear aromatic hydrocarbons. Int. J. M ass Spectrom. 201, 283-295 (2000).

23. Östman, P., Pakarinen, J.M .H., Vainiotalo, P., Franssila, S., Kostiainen, R., Kotiaho, T.: M inimum proton affinity for efficient ionization with atmospheric pressure desorption/ionization on silicon mass spectrometry. Rapid Commun. Mass Spectrom. 20, 3669-3673 (2006).

24. Anstead, G.M., Kym, P.R.: Benz[a]anthracene diols: Predicted carcinogenicity and structure-estrogen receptor binding affinity relationships. Steroids. 60, 383-394 (1995).

25. Leopoldini, M ., Pitarch, I.P., Russo, N., Toscano, M.: Structure, Conformation, and Electronic Properties of Apigenin, Luteolin, and Taxifolin Antioxidants. A First Principle Theoretical Study. J. Phys. Chem. A. $108,92-96$ (2004).

26. Zhang, D., Liu, Y., Chu, L., Wei, Y., Wang, D., Cai, S., Zhou, F., Ji, B.: Relationship Between the Structures of Flavonoids and Oxygen Radical Absorbance Capacity Values: A Quantum Chemical Analysis. J. Phys. Chem. A. 117, 1784-1794 (2013). 
27. Simonsick, W.J., Hites, R.A.: Characterization of high molecular weight polycyclic aromatic hydrocarbons by charge exchange chemical ionization mass spectrometry. Anal. Chem. 58, 2114-2121 (1986).

28. Kauppila, T.J., Bruins, A.P., Kostiainen, R.: Effect of the solvent flow rate on the ionization efficiency in atmospheric pressure photoionization-mass spectrometry. J. Am. Soc. M ass Spectrom. 16, 1399-1407 (2005)

29. Short, L.C., Cai, S.-S., Syage, J.A.: APPI-M S: Effects of M obile Phases and VUV Lamps on the Detection of PAH Compounds. J. Am. Soc. M ass Spectrom. 18, 589-599 (2007).

30. Robb, D.B., Blades, M.W.: Effects of Solvent Flow, Dopant Flow, and Lamp Current on Dopant-Assisted Atmospheric Pressure Photoionization (DA-APPI) for LC-MS. Ionizationvia Proton Transfer. J. Am. Soc. Mass Spectrom. 16, 1275-1290 (2005).

31. Klee, S., Albrecht, S., Derpmann, V., Kersten, H., Benter, T.: Generation of ion-bound solvent clusters as reactant ions in dopant-assisted APPI and APLI. Anal. Bioanal. Chem. 405, 6933-6951 (2013).

32. Kauppila, T.J., Kuuranne, T., Meurer, E.C., Eberlin, M.N., Kotiaho, T., Kostiainen, R.: Atmospheric pressure photoionization mass spectrometry. Ionization mechanism and the effect of solvent on the ionization of naphthalenes. Anal. Chem. 74, 5470-5479 (2002).

33. Kostko, O., Belau, L., Wilson, K.R., Ahmed, M.: Vacuum-Ultraviolet (VUV) Photoionization of Small Methanol and Methanol-Water Clusters. J. Phys. Chem. A. 112, 9555-9562 (2008).

34. Martrenchard, S., Grégoire, G., Dedonder-Lardeux, C., Jouvet, C., Solgadi, D.: Proton transfer mechanism in the ionic methanol dimer. PhysChemComm. 4, (1999).

35. Robb, D.B., Blades, M.W.: State-of-the-art in atmospheric pressure photoionization for LC/MS. Anal. Chim. Acta. 627, 34-49 (2008).

36. Knochenmuss, R., Cheshnovsky, O., Leutwyler, S.: Proton transfer reactions in neutral gas-phase clusters: 1-Naphthol with $\mathrm{H}_{2} \mathrm{O}, \mathrm{D}_{2} \mathrm{O}, \mathrm{CH}_{3} \mathrm{OH}, \mathrm{NH}_{3}$ and piperidine. Chem. Phys. Lett. 144, 317-323 (1988). 
37. Lorenz, M., Schiewek, R., Brockmann, K.J., Schmitz, O.J., Gäb, S., Benter, T.: The Distribution of Ion Acceptance in Atmospheric Pressure Ion Sources: Spatially Resolved APLI Measurements. J. Am. Soc. Mass Spectrom. 19, 400-410 (2008).

38. Asperger, A., Efer, J., Koal, T., Engewald, W.: On the signal response of various pesticides in electrospray and atmospheric pressure chemical ionization depending on the flow-rate of eluent applied in liquid chromatography-tandem mass spectrometry. J. Chromatogr. A. 937, 65-72 (2001).

39. Garcia, D.M., Huang, S.K., Stansbury, W.F.: Optimization of the atmospheric pressure chemical ionization liquid chromatography mass spectrometry interface. J. Am. Soc. Mass Spectrom. 7, 59-65 (1996).

40. Blanksby, S.J., Ellison, G.B.: Bond dissociation energies of organic molecules. Acc. Chem. Res. 36, 255263 (2003).

41. Kersten, H., Funcke, V., Lorenz, M., Brockmann, K.J., Benter, T., O'Brien, R.: Evidence of Neutral Radical Induced Analyte Ion Transformations in APPI and Near-VUV APLI. J. Am. Soc. Mass Spectrom. 20, 18681880 (2009). 